\title{
Occupational asthma in a factory with a contaminated humidifier
}

\author{
P SHERWOOD BURGE, M FINNEGAN, N HORSFIELD, D EMERY, P AUSTWICK, \\ PS DAVIES, CAC PICKERING
}

From the Department of Thoracic Medicine, East Birmingham Hospital, Birmingham; the Department of Thoracic Medicine, Wythenshawe Hospital, Manchester; and the Group for Occupational Lung Diseases Aerobiology Unit, Department of Allergy and Clinical Immunology, Cardiothoracic Institute, Brompton Hospital, Frimley, Surrey

ABSTRACT Thirty five printers who had work related wheeze, chest tightness, or breathlessness kept two hourly records of their peak expiratory flow for at least two weeks. They all worked in a factory supplied by air from contaminated humidifiers. The peak flow records showed consistent work related deterioration in 15 workers, nine of whom had a diurnal variation in peak flow exceeding $20 \%$. Ten workers kept further records after the humidifiers had been cleaned, other work practices remaining unchanged. There was substantial improvement in all 10 workers, implying that material from the contaminated humidifier was the cause of the work related changes in peak flow. The patterns of work related changes in peak flow fell into four groups: falls maximal on the first work day, falls maximal midweek, falls equivalent each work day, and falls progressive throughout the working week. Three quarters of this last group had immediate prick test responses to humidifier antigen, which were negative in all the others with work related changes in peak flow. This suggests that the progressive daily deterioration pattern alone is due to an IgE mediated response to humidifier antigens. A large range of microorganisms was identified in the humidifiers. No single microorganism appeared to be the antigen responsible for the precipitating antibody seen in $75 \%$ of the study population.

Industrial humidifiers are now a well recognised source of respiratory problems, such as humidifier fever and allergic alveolitis; but so far there have been no reports of any association with occupational asthma. Although the cause of these diseases is as yet unknown the excessive growth of microorganisms within the humidification system seems to be a common factor to all outbreaks, and there is every possibility that these organisms or their metabolites are capable of acting on more than one element of the immune system.

The control of humidity is of primary importance in certain industries, especially in printing, where the size of paper sheets varies with changes in their water content; and it is also necessary for comfort to maintain a minimum of $40 \%$ relative humidity level

Address for reprint requests: Dr PS Burge, Department of Thoracic Medicine, East Birmingham Hospital, Birmingham B9 5ST.

Accepted 22 October 1984 in air conditioned buildings. Dry air causes soreness of the eyes, nose and throat in a large proportion of exposed workers and it is especially liable to occur when the external ambient air is cold; but high humidity levels can also cause "oppressive" working atmospheres.

Water spray humidifiers concentrate airborne microorganisms, which are washed out of the incoming air, while other microorganisms are derived from the incoming mains water. Cellulose fibres carried back to the humidifier in the return air from a printing works, for example, may provide a suitable culture medium. Humidifier fever is the most widely recognised occupational disease in workers exposed to such humidifiers. ${ }^{1}$ The disease usually occurs on the first day after a period off work. After four to eight hours at work malaise, joint pains, headache, fever, cough, and breathlessness develop. They may be severe in the hours after exposure but then resolve over 12-16 hours. Affected workers have precipitating antibodies to antigens extracted from 
the water and sludge of the associated humidifiers, but lower titres of similar antibodies are found in many exposed but unaffected workers. Workers with humidifier fever have a normal chest radiograph and do not develop fibrotic lung disease even after repeated episodes. Extrinsic allergic alveolitis with pulmonary infiltrates and eventual fibrosis may also result from exposure to domestic and industrial humidifiers. ${ }^{23}$ This disease resembles farmer's lung and may be due to thermophilic actinomycetes in the humidifier, but so far it has only been described in the United States.

We describe an outbreak of occupational asthma in a printing works in which the principal activities were the printing of stationery for computer applications and security printing (such as cheques). The building was supplied with air from two large water spray humidifiers, in which extensive microbial growth had occurred. There was recirculation of both water in the humidifier and a proportion of return air from the factory. A preliminary survey of the factory identified 47 workers with chest tightness, wheeze, breathlessness, or difficulty with breathing that improved on days away from work. The aims of the study were to try to document changes in peak flow in workers with respiratory symptoms that improved on days away from work and to describe the different patterns of airways response in the workers with symptoms.

\section{Materials and methods}

An attempt was made to obtain serial records of peak flow from the 47 affected workers with work related respiratory symptoms, a mini Wright peak flow meter being used. Thirty six workers were seen briefly and given instruction in the measurement of peak flow. The remaining 11 were sent their meters with written instructions alone. Workers were asked to record their peak flow every two hours from waking to sleeping for two weeks. On each occasion at least three separate blows were to be made and the best recorded. If the best two blows were not within 20 litres/min of each other then further recordings were to be made until this reproducibility was achieved. Any treatment was kept constant on days at work and days off work, and the time at work was recorded daily. The records were plotted and assessed by standardised methods. ${ }^{4-6}$ The mean daily peak flow was calculated for the 24 hours starting with the first reading at work; this mean was plotted with the maximum and minimum peak flow in each 24 hours, with differentiation between days at work and days at home (figs 1-5). The maximum diurnal variation in peak flow was calculated by expressing the difference between the highest and the lowest value in each 24 hour period as a percentage of the highest value. The first two days were excluded from this calculation as the diurnal variation is often wider during this learning period. Each record was assessed without identification of patients to record (a) any deterioration during each of the two "weeks" at work and (b) any improvement during each of the two "weekends" away from work. Definite work related changes were diagnosed if at least three of the four weeks and weekends showed definite changes. Deterioration patterns were classified as worst on the first day of work, equivalent each work day, or progressively deteriorating with each work day's exposure. ${ }^{4}$ In addition, a new pattern was seen with a midweek maximal deterioration and with definite improvement at the end of the working week. Records were classified as inadequate if there were no periods at work, if there were many missing readings, or if major changes in treatment had occurred during the record. Ten workers were asked to keep further records of peak flow after the humidifiers had been cleaned.

Asthma was diagnosed when the diurnal variation in peak flow reached $20 \%$ or more on at least one day after the first two days. Definite work related changes were also seen in workers with a diurnal variation in peak flow of less than $20 \%$; these are evaluated separately.

Microbiological examinations were carried out on the humidifier water, the tank sediments, and the baffle plate deposits, conventional methods being used for bacteria, fungi, and protozoa; and several techniques for sampling airborne particulates were used on the printing floor.

Antigens were prepared from humidifier tank and mains water, slime (sludge) from the baffle plates, and air duct dust and also from glass fibre filters exposed in a Staplex air sampler. Each sample was treated with Coca's solution for five days followed by dialysis and freeze drying. The extracts were used at $10 \mathrm{mg} / \mathrm{ml}$ for skinprick tests and at $30 \mathrm{mg} / \mathrm{ml}$ for the precipitation plates with agar gel and double diffusion.

Three of those with work related asthma were exposed to air from other humidifiers in the factory. They have been omitted from the section dealing with specific antibodies to humidifier antigens as the antigens in these other humidifiers may have been different.

\section{Results}

Thirty six meters were handed to individual workers; three were not returned and the records from three were inadequate (two records kept for only three days, one was read to the nearest 50 litres/min 
only and also contained no time off work). Eleven meters were left with written instructions; at least three were not received because the workers had left or were on long term absence, one was not returned, and two were inadequate (one kept was for only three days, one averaged only three readings per day). Definite assessments could be made on 26 of $35(74 \%)$ of adequate records. Equivocal assessments were made in nine instances because there was only one day at work (1 case), only one day off work (2), progressive improvement or deterioration throughout the record (3), isolated low readings only (1), or a very irregular record (2). All of these problems could probably have been solved with longer records.

Consistent daily patterns of work related deterioration were seen in 15 workers. Nine of these fulfilled the physiological definition of asthma. Exactly similar changes were seen in six workers whose diurnal variation in peak flow never reached $20 \%$ (table 1). Four workers had progressive daily deterioration (fig 1), three equivalent daily deterioration (fig 2), and four midweek deterioration (fig 3). Deterioration that was maximal on the first work day was seen in four workers (fig 4) and was less consistent than the other patterns; in one case it was associated in the other week with a normal record and in another with a midweek deterioration, while the other two records both contained only one week at work.

Asthma which was not work related was seen in five workers. All had not more than one period of deterioration or recovery and had a diurnal variation in peak flow exceeding $30 \%$. One worker was taking cromoglycate, which may have masked a work related effect, and one had only three days at work (without any change during this period). Six workers had normal records, maximum diurnal variation being $11 \%$.

Table 1 Details of precipitating antibodies and immediate skin test responses to humidifier antigens and the results of peak flow records in the workers with occupational asthma

\begin{tabular}{|c|c|c|c|c|c|}
\hline $\begin{array}{l}\text { Patterns of peak } \\
\text { flow response }\end{array}$ & $\begin{array}{l}\text { Maximum diurnal } \\
\text { variation in peak } \\
\text { flow (\%) }\end{array}$ & $\begin{array}{l}\text { Maximum difference } \\
\text { between daily mean } \\
\text { peak flow (l/min) }\end{array}$ & $\begin{array}{l}\text { Precipitating } \\
\text { antibodies to } \\
\text { humidifier antigens }\end{array}$ & $\begin{array}{l}\text { Immediate skinprick } \\
\text { responses to } \\
\text { humidifier antigens }\end{array}$ & Atopic \\
\hline $\begin{array}{l}\text { Progressive } \\
\text { daily } \\
\text { deterioration } \\
\text { Equivalent daily } \\
\text { deterioration } \\
\text { Midweek } \\
\text { deterioration } \\
\text { First day } \\
\text { deterioration }\end{array}$ & $\begin{array}{r}44 \\
22 \\
17 \\
11 \\
29 \\
28 \\
7 \\
48 \\
48 \\
12 \\
11 \\
38 \\
29 \\
27 \\
13\end{array}$ & $\begin{array}{l}89 \\
44 \\
39 \\
35 \\
29 \\
58 \\
34 \\
79 \\
57 \\
35 \\
38 \\
51 \\
17 \\
70 \\
28\end{array}$ & $\begin{array}{l}++ \\
+ \\
- \\
+ \\
\text { Separate } \\
+ \\
+++ \\
+++ \\
+++ \\
+ \\
++++ \\
\text { Separate } \\
+++ \\
\text { Separate }\end{array}$ & $\begin{array}{l}+ \\
- \\
+ \\
+ \\
\text { Humidifier } \\
- \\
- \\
- \\
- \\
- \\
- \\
\text { Humidifier } \\
- \\
\overline{\text { Humidifier }}\end{array}$ & $\begin{array}{l}\overline{+} \\
+ \\
+ \\
- \\
- \\
- \\
- \\
- \\
- \\
- \\
- \\
+\end{array}$ \\
\hline
\end{tabular}

Fig 1 Maximum, mean, and minimum peak flow in a service operator. Days at work have a shaded background, days at home a clear background. The humidifier was cleaned between the two halves of the record. The first 14 days show progressive daily deterioration during each working week with a three day recovery pattern at the weekend, so that the furst day at work is the best day each week. After the humidifier had been cleaned there is still discernible but trivial deterioration of a similar pattern related to work.

Precipitating antibodies to humidifier antigens were present in $75 \%$ of those with occupational asthma, but were also present in $60 \%$ of symptomless exposed workers $(p>0.1)($ table 2$)$. Skinprick tests with humidifier antigens were positive in $3 / 12$ workers with occupational asthma exposed to the principal humidifiers from which antigens were prepared (table 1). All three of these had occupational asthma with a progressive daily deterioration pattern. Nine per cent of symptomless workers had

positive skinprick responses to humidifier antigens.

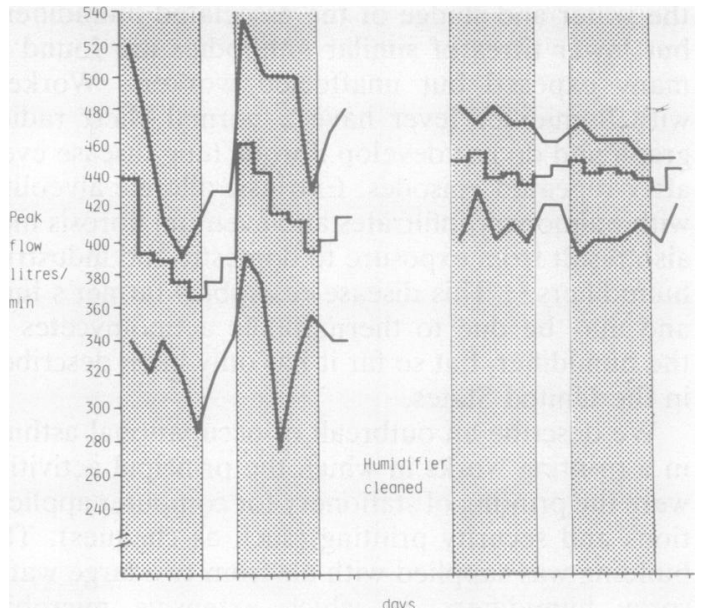


Table 2 Antibodies to humidifier antigens in workers with occupational asthma and symptomless workers exposed to principal humidifiers

\begin{tabular}{|c|c|c|c|c|c|c|c|c|}
\hline & \multirow{3}{*}{$\begin{array}{l}\text { No of } \\
\text { workers }\end{array}$} & \multirow{3}{*}{$\begin{array}{l}\text { Atopic to } \\
\text { domestic } \\
\text { allergens (\%) }\end{array}$} & \multicolumn{6}{|l|}{ Humidifier antigens } \\
\hline & & & \multirow{2}{*}{$\begin{array}{l}\text { Immediate } \\
\text { skinprick response } \\
\text { (\% positive) }\end{array}$} & \multicolumn{5}{|c|}{ Precipitating antibodies (\%) } \\
\hline & & & & 0 & + & ++ & +++ & +++ \\
\hline $\begin{array}{l}\text { Without symptoms } \\
\text { Occupational asthma }\end{array}$ & $\begin{array}{r}192 \\
12\end{array}$ & $\begin{array}{l}32 \\
25\end{array}$ & $\begin{array}{r}99 \\
25\end{array}$ & $\begin{array}{l}40 \\
25\end{array}$ & $\begin{array}{l}15 \\
25\end{array}$ & $\begin{array}{r}22 \\
8\end{array}$ & $\begin{array}{l}22 \\
34\end{array}$ & $\begin{array}{l}1 \\
8\end{array}$ \\
\hline
\end{tabular}

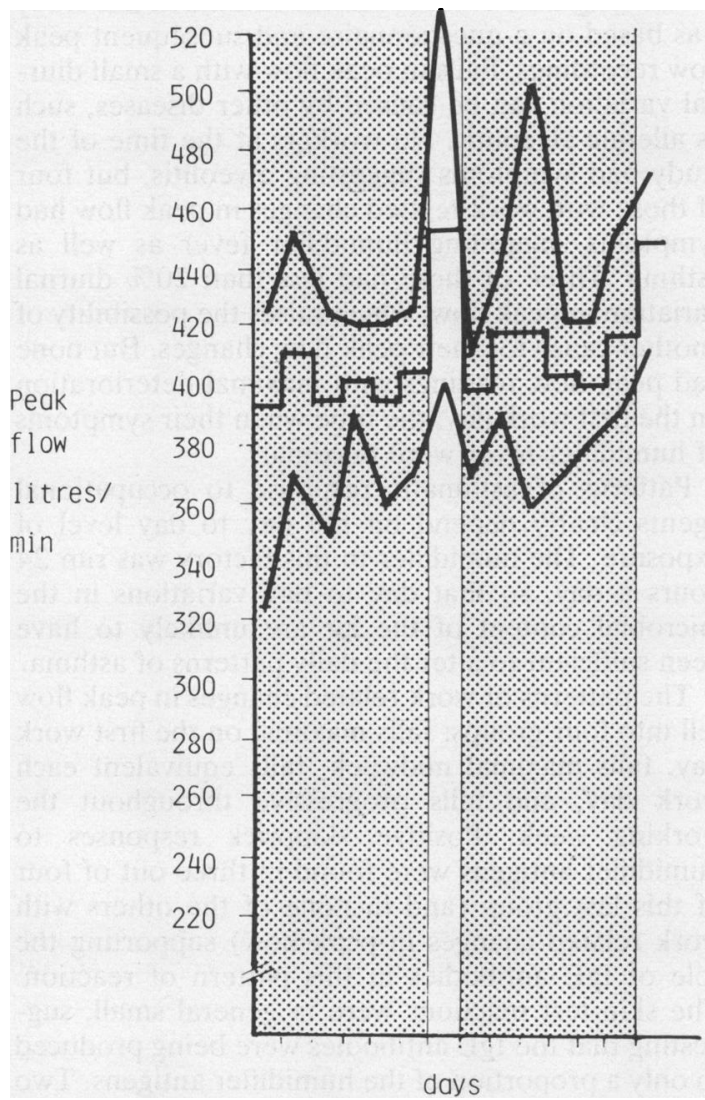

Fig 2 Maximum, mean, and minimum peak flow in a foreman showing equivalent daily deterioration in each working week.

Ten workers kept a second two week record of peak flow after the humidifiers had been cleaned (fig 1). All were improved; the changes seen in peak flow records were all less noticeable. Four still showed some recognisable differences between days at home and at work.

Direct examination of the tank water and sludge and the baffle jelly showed very large numbers of bacteria, fungal hyphae, and spores and some protozoa and nematodes. Isolations from these

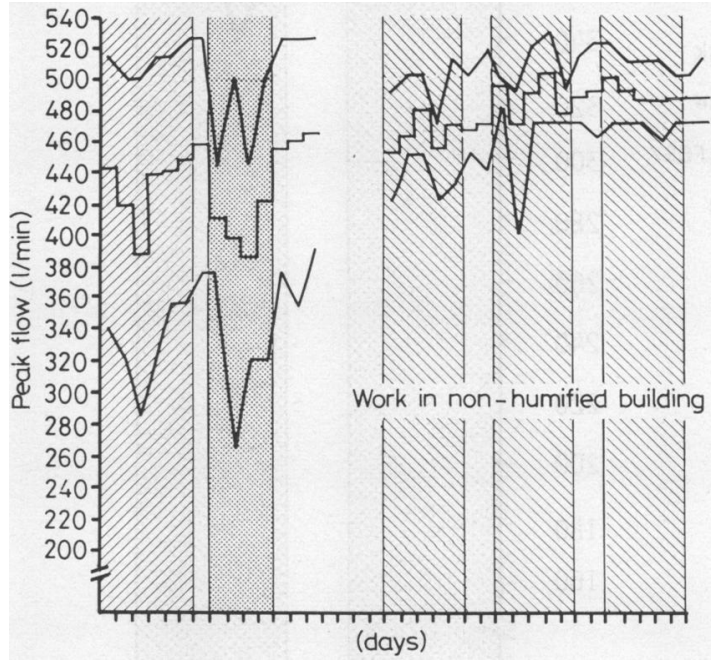

Fig 3 Maximum, mean, and minimum peak flow in a keyboard operator who was working on a 1400-2200 hour shift in the furst week at work and an 0600-1400 hour shift in the second week at work. It shows deterioration maximal midweek in each week. He was then sent on a training course, during which he worked from 0900 to 1700 hours for three weeks in a separate building without a humidifier. There is improvement throughout the first two weeks at work with abolition of asthma in the third week.

materials gave a wide range of organisms, the most frequent of which are listed in table 3 .

Antigen extracts were also made from the cultured organisms and tested by double diffusion for precipitins. The results of these tests are presented in table 2. None of the individual organisms grown in pure culture (that is, those marked with an asterisk in table 3) when extracted and freeze dried elicited an immunological response in the precipitin test.

\section{Discussion}

In this factory the humidifier water clearly became a good culture medium for a wide range of nonpathogenic organisms during the operation of the spray type system, and water and slime extracts 


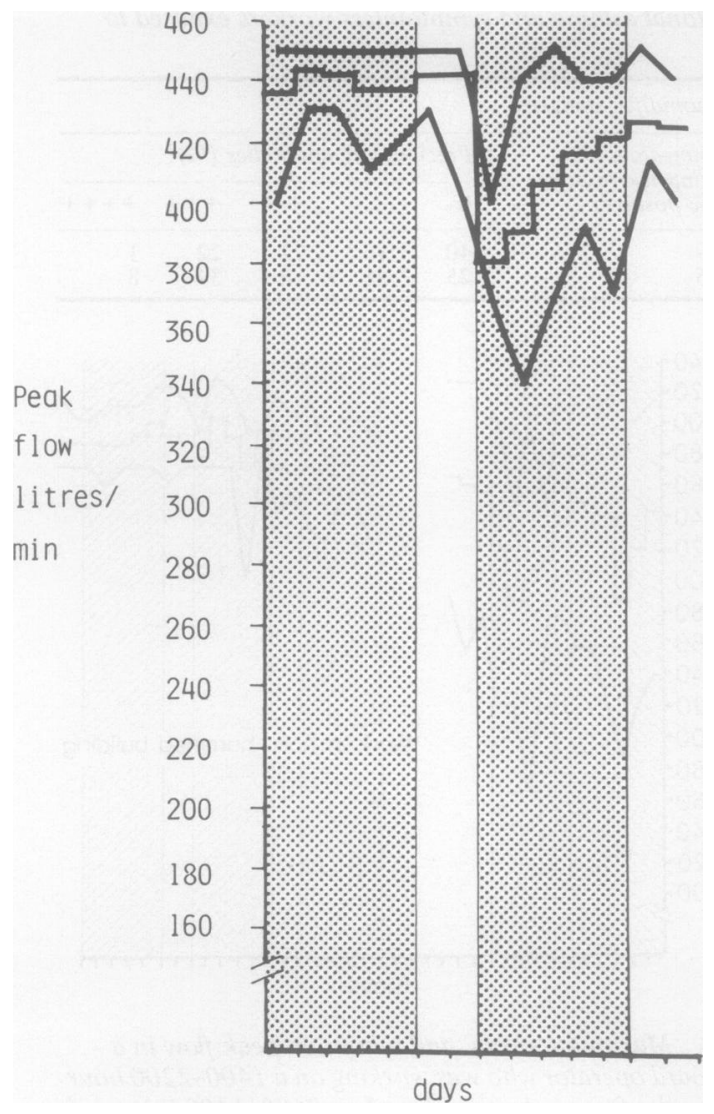

Fig 4 Maximum, mean, and minimum peak flow in a filing clerk. There is a normal first week at work followed by a first day deterioration pattern in the second working week.

elicited an immune (IgG) response in $65 \%$ of those seen. In this group 12 cases of humidifier fever were diagnosed.

Perhaps surprisingly, occupational asthma from this source has not been described before. Some of

Table 3 Organisms isolated from the humidifier

\begin{tabular}{|c|c|}
\hline FUNGI & BACTERIAL AND ACTINOMYCETES \\
\hline $\begin{array}{l}{ }^{*} \text { Alternaria spp } \\
{ }^{*} \text { Aspergillus fumigatus } \\
{ }^{*} \text { Aureobasidium pullulans } \\
\text { *'Cephalosporium spp } \\
\text { Chaetomium spp } \\
\text { C'Cladosporium spp } \\
{ }^{*} \text { Fusarium spp } \\
{ }^{*} \text { Humicola spp } \\
{ }^{*} \text { Mortierella zychae } \\
\text { "Oidodendron spp } \\
\text { "Oenicillium spp } \\
{ }^{*} \text { Phialophora spp } \\
{ }^{*} \text { Phoma spp } \\
{ }^{*} \text { Rhodotorula spp }\end{array}$ & $\begin{array}{l}\text { *Alkaligenes spp } \\
\text { *Bacillus spp } \\
\text { (mesophilic and thermophilic) } \\
\text { *Micrococcus spp } \\
\text { *Pseudomonas spp } \\
\text { *Sphaerotilus natans } \\
\text { *Staphylococcus epidermidis } \\
\text { * Streptomyces albus } \\
\text { Streptomyces } \\
{ }^{*} \text { Thermoactinomyces vulgaris } \\
\text { PROTOzoA } \\
{ }^{*} \text { Acanthamoba polyphagii } \\
{ }^{*} \text { Hartmanella vermiformis } \\
\text { Vahlkamfia inornata } \\
\text { Oikomonas terno }\end{array}$ \\
\hline
\end{tabular}

*Tested for antigenic (precipitin) acitivity. the fungi present are common causes of seasonal asthma-for instance, Alternaria and Cladosporium-but their concentrations in the humidifier water and in the factory air were low. Solomon ${ }^{7}$ has, however, reported that a domestic humidifier contaminated with many fungi, including Rhodotorula, precipitated asthma in two asthmatic subjects who used cold mist vapourisers for the treatment of pre-existing disease.

The diagnosis of work related asthma in this study was based on a questionnaire and subsequent peak flow recordings. Falls in peak flow with a small diurnal variation can be caused by other diseases, such as allergic alveolitis. No workers at the time of the study had symptoms suggesting alveolitis, but four of those with work related changes in peak flow had symptoms suggesting humidifier fever as well as asthma. Three of these had less than $20 \%$ diurnal variation in peak flow, which raises the possibility of another cause for their peak flow changes. But none had peak flow readings with maximal deterioration on the first work day, the time when their symptoms of humidifier fever were maximal.

Patterns of asthmatic response to occupational agents clearly depend on the day to day level of exposure. The humidifier in this factory was run 24 hours a day, so that day to day variations in the microbial content of the air are unlikely to have been sufficient to alter the daily patterns of asthma.

The patterns of work related changes in peak flow fell into four groups: falls maximal on the first work day, falls maximal midweek, falls equivalent each work day, and falls progressive throughout the working week. Positive skinprick responses to humidifier antigens were found in three out of four of this last group (and in none of the others with work related changes in peak flow) supporting the role of IgE antibodies in this pattern of reaction. The skin test reactions were in general small, suggesting that the IgE antibodies were being produced to only a proportion of the humidifier antigens. Two groups showed improvements in peak flow despite continual work exposure - that is, asthma deterioration maximal on the first work day and maximal midweek. Repeated daily challenges occasionally lead to tolerance, but only when the allergen dose is kept below that causing asthma. ${ }^{8}$ Those with asthma maximal on the first work day have a definite fall in peak flow on that day, and therefore are unlikely to be in the process of becoming immunologically tolerant to an allergen. The pattern with midweek deterioration with subsequent recovery despite continuing exposure is likely to represent an exaggerated form of the reaction pattern with maximal deterioration on the first work day. Skinprick responses to humidifier antigens were negative in all 


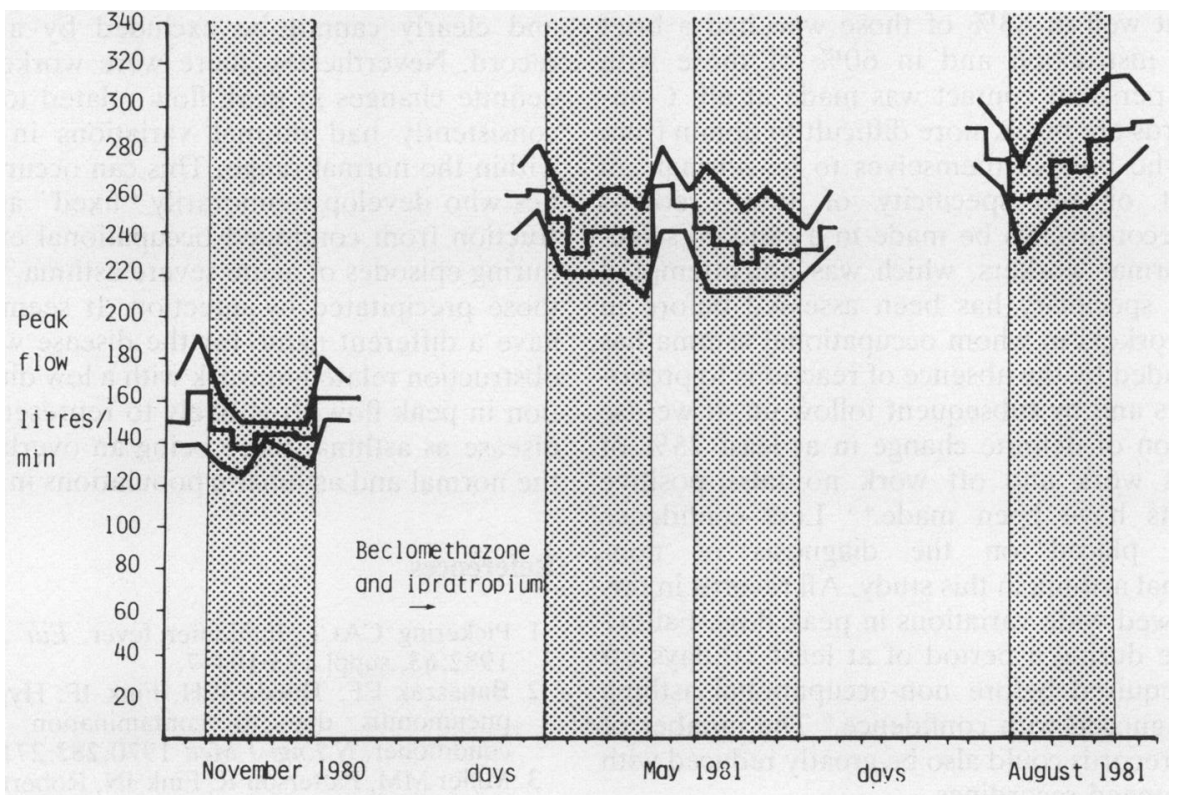

Fig 5 Maximum, mean, and minimum peak flow in an accountant. There is trivial diurnal variation throughout. During the first week at work he had no treatment and the record shows a small drop in peak flow related to days at work. The second two parts of the record were made while he was taking beclomethasone and ipratropium. There are small deteriorations at work in each of the three working weeks, with a borderline pattern in the first two weeks (between equivalent deterioration and progressive deterioration) and a first day deterioration pattern in the final working week.

those with occupational asthma showing these two patterns of reaction, suggesting that the mechanisms were different. It has been postulated that humidifier fever is caused by endotoxins, which can be measured in the air." Tolerance to endotoxin develops rapidly, but endotoxin exposure usually results in a febrile rather than an asthmatic response.

There are striking similarities between the respiratory diseases seen in cotton mills and those in buildings with contaminated humidifiers. Byssinosis is the classical disease with symptoms maximal on the first work day, with subsequent improvement despite continuing exposure. Other patterns of response are also seen, however, particularly asthma with progressive daily deterioration (CAC Pickering, unpublished observations).

Precipitating antibodies to humidifier antigens, which are likely to contain considerable endotoxin, were found in all groups with occupational asthma in a similar proportion to that found in symptomless exposed workers. Precipitins were found in all workers from the factory with humidifier fever but were absent in three workers with occupational asthma, suggesting that IgG precipitating antibodies were a marker of exposure rather than of aetiological significance in those with occupational asthma.

Peak flow records of the type described can only detect work related changes and do not specify the cause. There were no other widespread causes of occupational asthma in this factory; the improvement seen in all records when the humidifiers were cleaned shows that the humidifiers were the source of the outbreak. No other modification took place to the working environment during this period.

Two hourly recordings of peak flow have not been assessed in epidemiological studies before. These records now have an established place in the hospital work up of patients with suspected occupational asthma, when contact with the physician is more formal and much more time is available. In an outpatient setting satisfactory records of peak flow can nearly always be obtained, although several visits may be needed to achieve them. Workers seen in epidemiological surveys are different; there is no ordinary doctor-patient relationship and the worker rarely puts himself in the role of patient. It is therefore surprising that these demanding records were 
carried out well in $83 \%$ of those who had a brief period of instruction and in $60 \%$ of those with whom no personal contact was made at all. Complete records are much more difficult to obtain from workers who believe themselves to be normal; an assessment of the specificity of these records requires recordings to be made in a random selection of normal workers, which was not attempted here. The specificity has been assessed before in selected workers in whom occupational asthma has been excluded by the absence of reactions to provocation tests and by subsequent follow up. If we use the criterion of definite change in at least $75 \%$ of periods at work and off work no false positive assessments have been made. ${ }^{45}$ Less confidence could be placed on the diagnosis of nonoccupational asthma in this study. All records in this group showed wide variations in peak flow. Failure to improve during a period of at least 10 days off work is required before non-occupational asthma can be diagnosed with confidence. ${ }^{6}$ The number of equivocal records could also be greatly reduced with more prolonged recordings.

Peak flow recordings proved a useful method of biological monitoring in this factory. A humidifier could not be sterilised for more than a few hours; the need for microbiological control can be assessed by monitoring sensitised workers. The effect of prolonged exposure to humidifier antigens is unknown. One of the affected workers who had been exposed for 10 years had developed severe, largely fixed airways obstruction (fig 5). It is at least possible that repeated exposures could have contributed to this.

This study raises a problem about the definition of asthma. Asthma is a disease characterised by airways obstruction, which alters its severity over short periods of time. Hetzel and Clark ${ }^{10}$ found that the diurnal variation in peak flow (computed from a cosinor analysis and using the mean peak flow as the denominator) averaged $8.3 \%$ with a standard deviation of $5.2 \%$ in normal subjects. Asthma (or excess diurnal variation in peak flow) may be intermittent and clearly cannot be excluded by a two week record. Nevertheless, there were workers showing definite changes in peak flow related to work who consistently had diurnal variations in peak flow within the normal range. This can occur in asthmatics who develop temporarily "fixed" airways obstruction from continued occupational exposure ${ }^{6}$ or during episodes of acute severe asthma, particularly those precipitated by infection. It seems a pity to have a different name for the disease with airways obstruction related to work with a low diurnal variation in peak flow. It is likely to represent the same disease as asthma, there being an overlap between the normal and asthmatic populations in this index.

\section{References}

1 Pickering CAC. Humidifier fever. Eur J Respir Dis 1982;63, suppl 123:104-7.

2 Banaszak EF, Thiede WH, Fink JF. Hypersensitivity pneumonitis due to contamination of an airconditioner. $N$ Engl J Med 1970;283:271-6.

3 Miller MM, Patterson R, Fink JN, Roberts R. Chronic hypersensitivity lung disease with recurrent episodes of hypersensitivity pneumonitis due to contaminated central humidifier. Allergy 1976;6:451-62.

4 Burge PS, O'Brien IM, Harries MG. Peak flow records in the diagnosis of occupational asthma due to colophony. Thorax 1979;34:308-16.

5 Burge PS, O'Brien IM, Harries MG. Peak flow rate records in the diagnosis of occupational asthma due to isocyanates. Thorax 1979;34:317-23.

6 Burge PS. Single and serial measurements of lung function in the diagnosis of occupational asthma. Eur $J$ Respir Dis 1982;63, suppl 123:47-59.

7 Solomon WR. Fungus aerosols arising from cold-mist vaporisers. J Allergy 1974;54:222-8.

8 Herxheimer H, Prior FN. Further observations on induced asthma and bronchial hyposensitisation. Int Arch Allergy 1952;3:189-207.

9 Rylander R. Bacteria as aetiological agents in byssinosis and other lung diseases. Eur J Respir Dis $1982 ; 63$, suppl 123:34-46.

10 Hetzel MR, Clark TJH. Comparison of normal and asthmatic circadian rhythms in peak expiratory flow rate. Thorax 1980;35:732-8. 